\title{
Erratum to: Synthesis of novel MMT/acyl-protected nucleo alanine monomers for the preparation of DNA/alanyl-PNA chimeras
}

\author{
G. N. Roviello • S. Gröschel • C. Pedone • \\ U. Diederichsen
}

Published online: 21 April 2010

(C) Springer-Verlag 2010

Erratum to: Amino Acids

DOI 10.1007/s00726-009-0324-x

Scheme 1 was incorrect and is reproduced correctly here.

The online version of the original article can be found under doi:10.1007/s00726-009-0324-x.

G. N. Roviello · S. Gröschel · U. Diederichsen ( $\square)$

Institut für Organische und Biomolekulare Chemie,

Georg-August-Universität Göttingen, Tammannstr. 2,

37077 Göttingen, Germany

e-mail: udieder@gwdg.de

G. N. Roviello - C. Pedone

Istituto di Biostrutture e Bioimmagini-CNR,

Via Mezzocannone 16, 80134 Naples, Italy 
1312

G. N. Roviello et al.

Scheme 1 Synthesis of

Boc- and MMT-protected

nucleo amino acids with acyl

protected nucleobases
1. TFA, $1 \mathrm{~h}$

2. MMTCl, $\mathrm{NEt}_{3}$, DMF

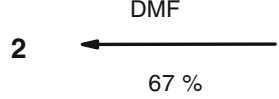

7

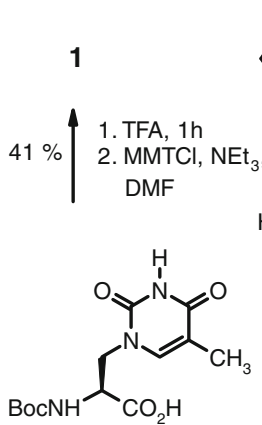

6

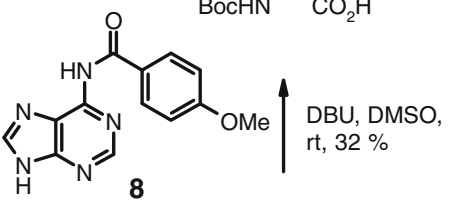

8
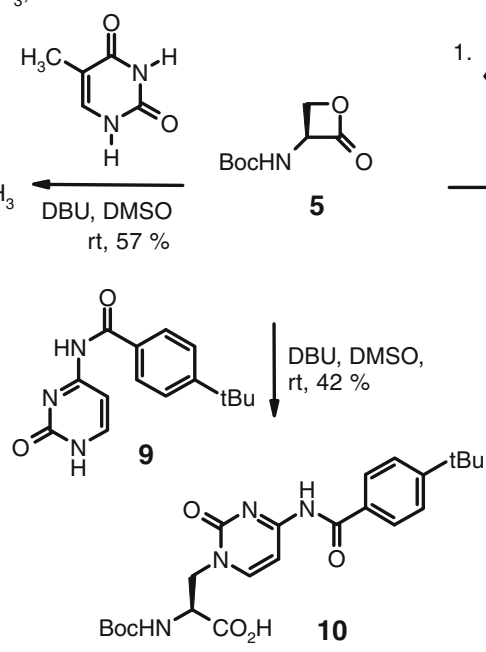

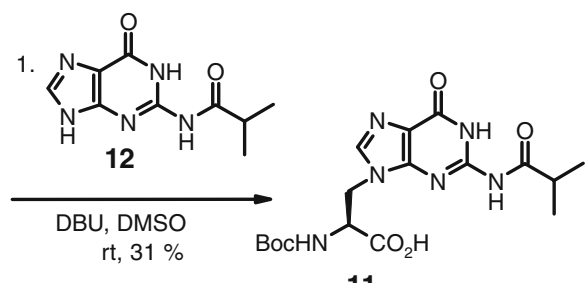

11

1. TFA, $2 \mathrm{~h}$

$31 \%$ 2. MMTCl, $\mathrm{NEt}_{3}$, DMF

1. TFA, $2 \mathrm{~h}$

2. MMTCl, $\mathrm{NEt}_{3}$, DMF $25 \%$

4

3

Springer 